\title{
Meta-Regression models describing the effects of essential oils and added lactic acid bacteria on pathogen inactivation in cheese
}

\author{
Beatriz Nunes Silva ${ }^{\mathrm{a}, \mathrm{b}}$, Vasco Cadavez ${ }^{\mathrm{a}}$, José António Teixeira ${ }^{\mathrm{b}}$, Ursula Gonzales-Barron ${ }^{\mathrm{a}}$, \\ ${ }^{a}$ Centro de Investigação de Montanha (CIMO), Instituto Politécnico de Bragança, Campus de Santa Apolónia, 5300-253 Bragança, Portugal \\ ${ }^{\mathrm{b}}$ CEB - Centre of Biological Engineering, University of Minho, Campus Gualtar, 4710-057 Braga, Portugal
}

\section{A R T I C L E I N F O}

\section{Keywords:}

Biopreservation

Starter culture

Antimicrobials

Mixed-effects model

Meta-analysis

\begin{abstract}
A B S T R A C T
Biopreservatives such as plant-based antimicrobials and bacteriocinogenic starter cultures have been proposed as hurdles to increase microbiological safety of a variety of products, including cheese, and numerous studies have reported their pathogen inhibitory properties. For that reason, the objective of this meta-analysis was to summarise the inactivation of Listeria monocytogenes (LM), Staphylococcus aureus (SA) and Salmonella spp. (SS) in cheese attained by added lactic acid bacteria (LAB) and essential oils (EOs); and to compare the inhibitory effectiveness by application mode and specific antimicrobial. After systematic review, 1810 observations on log reduction data and study characteristics were extracted from 53 studies. Comparing among the factual methods of application of antimicrobials (in milk, cheese surface and incorporated in films), meta-regression models pointed out that addition of EOs to milk renders, as a whole, the lowest inhibitory effect against LM, SA and SS in the finished product; whereas for added LAB, incorporation in milk prompts a faster inactivation of LM than onto cheese surface. Lemon balm, sage and basil EOs showed the best inhibitory outcomes against LM and SA; whereas clove, oregano and bay EOs presented the highest bactericidal effect against SS. For a given increase in EO concentration, the application on cheese surface provides the greatest inhibitory effect against LM and SS, while EO-embedded films lead to a more rapid inactivation during maturation/storage. The experimental practice of inoculating the antimicrobial in cheese mixture should no longer be employed in challenge studies, since the meta-regression models have demonstrated that this application method biases the results, overestimating or underestimating the inhibitory effects of EOs or added LAB, respectively. This meta-analysis has also emphasised the need to further investigate the relationship between pathogen's inoculum size and their concentrations in time.
\end{abstract}

\section{Introduction}

Listeria monocytogenes (LM), Staphylococcus aureus (SA) and Salmonella spp. (SS) are some of the most common bacterial agents causing foodborne illnesses and are found in numerous food matrices, including different types of cheeses (Iannetti et al., 2016; Jackson et al., 2018; Rosengren et al., 2010; Kousta et al., 2010; Cremonesi et al., 2007; Almeida et al., 2007; Tekinşen and Özdemir, 2006; Cunha-Neto et al., 2019; Elafify et al., 2019). A recent meta-analysis showed pooled prevalence of $12.8 \%$ for LM and $16 \%$ for SA in goat raw milk cheeses, while the prevalence of SS was lower (5.91\%), but still concerning (Gonzales-Barron et al., 2017). LM and SS can cause illnesses even when in low numbers in any food product, including cheese (United States Food and Drug Administration 2003). On the other hand, a larger number of SA (above $10^{5} \log \mathrm{CFU} / \mathrm{g}$ ) is required for this pathogen to be able to produce enterotoxins and impose a serious health threat (Duquenne et al., 2010). Nevertheless, SA imposes an important contamination issue since, even at low initial contamination levels, many factors can contribute to SA growth to a sufficiently high concentration that enables enterotoxin production in the curd/cheese (Paulin et al., 2012). Overall, soft and semi-soft cheeses made from different milk kinds and types (pasteurised, raw or low-heat-treated; and from cows, goats, sheep, etc.) sampled at retail level have revealed non-satisfactory results in terms of pathogen contamination by pathogens (EFSA and ECDC, 2018) thus underscoring the importance of improving the safety of cheeses to reduce the occurrence of pathogens.

Biopreservatives such as bacteriocinogenic lactic acid bacteria (LAB) used in starter cultures, and plant-based antimicrobials such as essential

\footnotetext{
* Corresponding author.

E-mail address: ubarron@ipb.pt (U. Gonzales-Barron).
} 
oils (EOs) are hurdles used to increase the microbiological safety of cheeses. The microbial inhibition offered by bacteriocinogenic LAB is mostly due to competition for substrates, production of antimicrobial substances (bacteriocins), production of organic acids that drop the $\mathrm{pH}$ during fermentation, and production of other non-proteinaceous compounds such as $\mathrm{H}_{2} \mathrm{O}_{2}$ (Tulini, 2014). The mechanism of action of EOs include a series of events on the cell surface, and, consequently, within the cytoplasm (Nazzaro et al., 2013). Modifications of membrane permeability and compromised transport of molecules can lead to degradation of the cell wall (damaging the cytoplasmic membrane), increased permeability (causing the leakage of cell contents), denaturation of enzymes and cellular proteins, loss of metabolites and ions (Nazzaro et al., 2013), and cytoplasm coagulation (Nazzaro et al., 2013; Gustafson et al., 1998).

Over the past years, several authors have performed challenge studies of foodborne pathogens inoculated in milk or cheese to assess the antimicrobial capacity of functional starter cultures or selected LAB (Ibrahim and Awad, 2018; Campagnollo et al., 2018; Atanasova et al., 2014) and plant-based antimicrobials (Artiga-Artigas et al., 2017; Wahba et al., 2010; Menon and Garg, 2001; Tehrani and Sadeghi, 2015; Dannenberg et al., 2016). Thus, a meta-analysis of the published results on the effect of antimicrobial biopreservatives will help evaluate their usefulness to control foodborne pathogens in cheeses (Xavier et al., 2014); and more specifically, compare the effectiveness of the different biopreservatives and modes of application. In this meta-regression study, the population is defined as cheeses with added lactic acid bacteria or essential oils, and the measured outcome is the mean log reduction of pathogens. This study aims to deliver an insight on the effects of biopreservation methods in cheese for the optimisation of these hurdle technologies to improve the safety of cheeses.

\section{Methods}

\subsection{Data collection and description of the data set}

Electronic literature search was carried out in Scopus, PubMed and Web of Science databases to find original and review articles, published since 2000, summarising biopreservation methods currently tested and/ or applied in cheese-making and their efficiencies against pathogens. The search was done systematically and aimed to find quality studies validated by the scientific community.

The bibliographic searches were conducted by properly applying the AND and OR logical connectors to combine terms regarding biopreservation and terms referring to biopreservatives characteristics and capacities in the selected products, as follows: (preservative OR biopreservati* OR biopreservati* OR "starter culture" OR starter OR "lactic acid bacteria" OR "essential oil" OR extract) AND (antimicrobial OR inhibitory OR natural OR plant OR functional) AND (activity OR capacity OR propert* OR effect) AND (cheese OR "fermented milk"). When studies referenced in the collected articles were not present in the results of the literature search, said references were added. Grey literature (research that has not undergone peer-review for publication) was not acquired to avoid data validity concerns and data duplication, since high-quality theses and reports are likely to be also published in peerreviewed journals. Other meta-analysis studies and systematic reviews were also excluded. The criteria for inclusion of data were: (i) the inoculum level, temperature of storage and antimicrobial concentration must be reported in the study; (ii) essential oils could not be mixed; (iii) if an antimicrobial film was used, the control must also be coated with the film but without the antimicrobial (as opposed to uncoated); and (iv) each study must have collected mean log reduction values at a certain time point (or, alternatively, it should provide mean microbial concentrations for the treated and control groups, so that reduction could be thereof calculated). This last criterion signifies that microbial reduction was relative to the control, and does not necessarily mean that microbial inactivation occurred in the treated group. Even if bacterial growth
Table 1

Distribution of log reduction data in L. monocytogenes (LM), S. aureus (SA) and Salmonella spp. (SS) by cheese descriptive category for the two bio-interventions strategies meta-analysed.

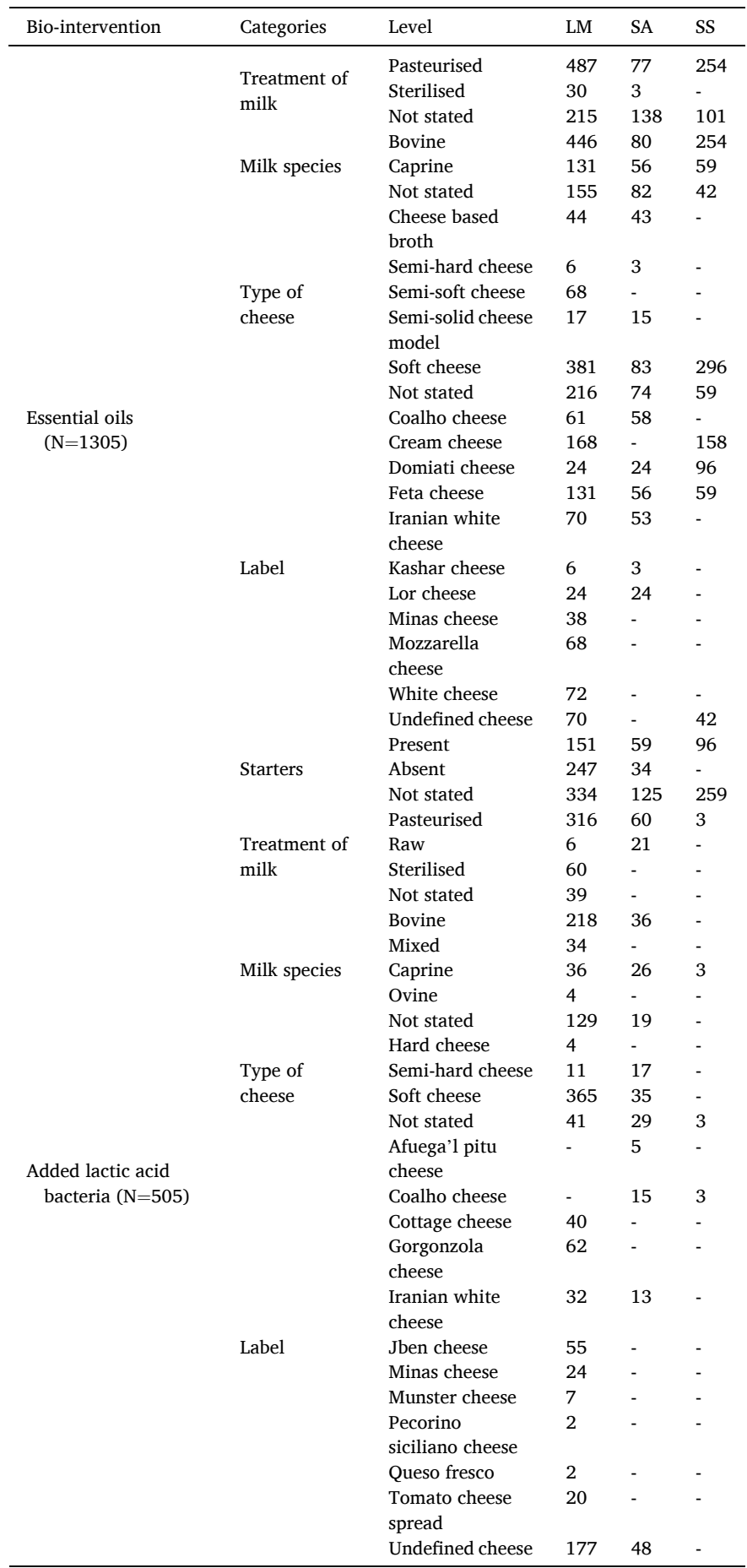

occurred in both control and treated groups, if it was lower in the treated group, the observation would be admitted into the meta-analytical data set.

After assessing all the information from all publications, 53 studies published from 2000 until August 2019 were considered appropriate for inclusion (Campagnollo et al., 2018; Menon and Garg, 2001; Tehrani and Sadeghi, 2015; Dannenberg et al., 2016; De Souza et al., 2016; Ghasemi et al., 2015; Govaris et al., 2011; Rolim et al., 2015; Martinez et al., 2015; Lourenco et al., 2017; da Costa et al., 2018; Benkerroum 
Table 2

Distribution of log reduction data in L. monocytogenes (LM), S. aureus (SA) and Salmonella spp. (SS) by moderator for the two bio-interventions strategies metaanalysed.

\begin{tabular}{|c|c|c|c|c|c|}
\hline $\begin{array}{l}\text { Bio- } \\
\text { intervention }\end{array}$ & Moderators & Level & LM & SA & SS \\
\hline \multirow{17}{*}{$\begin{array}{l}\text { Essential oils } \\
\qquad(\mathrm{N}=1305)\end{array}$} & \multirow{4}{*}{ Application type, App } & Mixture & 61 & 58 & 42 \\
\hline & & Film & 90 & 83 & 59 \\
\hline & & Milk & 221 & 77 & 96 \\
\hline & & Surface & 360 & 0 & 158 \\
\hline & \multirow{3}{*}{ Exposure time, $t$ (days) } & {$[0,30]$} & 676 & 178 & 323 \\
\hline & & {$[30,60]$} & 45 & 29 & 32 \\
\hline & & {$[60,75]$} & 11 & 11 & 0 \\
\hline & \multirow{3}{*}{$\begin{array}{l}\text { Storage temperature, } T \\
\left({ }^{\circ} \mathrm{C}\right)\end{array}$} & {$[4,15]$} & 690 & 210 & 355 \\
\hline & & {$[15,25]$} & 30 & 0 & 0 \\
\hline & & {$[25,35]$} & 12 & 8 & 0 \\
\hline & \multirow{3}{*}{$\begin{array}{l}\text { Inoculum level, Inoc (log } \\
\mathrm{CFU} / \mathrm{g} \text { or } \log \mathrm{CFU} / \mathrm{ml})\end{array}$} & {$[1.5,3.5]$} & 137 & 109 & 59 \\
\hline & & {$[3.5,5.5]$} & 447 & 27 & 180 \\
\hline & & {$[5.5,7]$} & 148 & 82 & 116 \\
\hline & \multirow{4}{*}{$\begin{array}{l}\text { Antimicrobial } \\
\text { concentration, Conc }(\% \mathrm{v} / \\
\mathrm{v} \text { or } \mathrm{w} / \mathrm{w})\end{array}$} & $\begin{array}{l}{\left[5 \times 10^{-3},\right.} \\
1.5]\end{array}$ & 663 & 168 & 311 \\
\hline & & {$[1.5,3]$} & 41 & 22 & 15 \\
\hline & & {$[3,4.5]$} & 28 & 28 & 29 \\
\hline & & Mixture & 0 & 11 & 3 \\
\hline \multirow{14}{*}{$\begin{array}{l}\text { Added lactic } \\
\text { acid bacteria } \\
(\mathrm{N}=505)\end{array}$} & \multirow[t]{3}{*}{ Application type, App } & Milk & 277 & 70 & 0 \\
\hline & & Surface & 144 & 0 & 0 \\
\hline & & {$[0,20]$} & 345 & 61 & 2 \\
\hline & \multirow[t]{2}{*}{ Exposure time, $t$ (days) } & {$[20,40]$} & 46 & 15 & 1 \\
\hline & & {$[40,75]$} & 30 & 5 & 0 \\
\hline & \multirow{3}{*}{$\begin{array}{l}\text { Storage temperature, } T \\
\left({ }^{\circ} \mathrm{C}\right)\end{array}$} & {$[4,10]$} & 259 & 40 & 3 \\
\hline & & {$[10,16]$} & 115 & 30 & 0 \\
\hline & & {$[16,22]$} & 47 & 11 & 0 \\
\hline & \multirow{3}{*}{$\begin{array}{l}\text { Inoculum level, Inoc (log } \\
\mathrm{CFU} / \mathrm{g} \text { or } \log \mathrm{CFU} / \mathrm{ml} \text { ) }\end{array}$} & {$[2,4]$} & 173 & 27 & 0 \\
\hline & & {$[4,6]$} & 153 & 24 & 0 \\
\hline & & {$[6,8]$} & 95 & 30 & 3 \\
\hline & Antimicrobial & {$[0.5,4]$} & 78 & 38 & 0 \\
\hline & concentration, Conc (log & {$[4,8]$} & 228 & 4 & 0 \\
\hline & $\begin{array}{l}\mathrm{CFU} / \mathrm{g}, \log \mathrm{CFU} / \mathrm{ml}, \% \mathrm{v} / \\
\mathrm{v} \text { or } \% \mathrm{w} / \mathrm{v})\end{array}$ & {$[8,12]$} & 115 & 39 & 3 \\
\hline
\end{tabular}

et al., 2000; Pingitore et al., 2012; Khay et al., 2014; Rilla et al., 2004; Achemchem et al., 2006; Torlak and Nizamlioglu, 2011; Hassanien et al., 2014; Ehsani et al., 2019; Izquierdo et al., 2009; Kavas and Kavas, 2016; Scatassa et al., 2017; Castro et al., 2018; Ehsani and Mahmoudi, 2013; Smith-Palmer et al., 2001; Rodríguez et al., 2005; Sadeghi et al., 2016; Hamedo and Abdelmigid, 2009; Dal Bello et al., 2012; Han et al., 2015; Morandi et al., 2019; Mahgoub et al., 2013; Ehsani et al., 2016; Sadeghi et al., 2013; Aspri, 2017; Azizkhani et al., 2016; Liu et al., 2008; Hamedi et al., 2014; Raeisi et al., 2014; de Carvalho et al., 2015; Coelho et al., 2014; Han et al., 2014; Abdelfatah and Mahboub, 2018; Tetili et al., 2017; Hassanzadazar et al., 2014; Mahmoudi et al., 2012; Gomes de Oliveira et al., 2014; Ben Slama et al., 2013; Nassim and Rihab, 2017; Langa et al., 2018; Medvedová et al., 2011; Kim et al., 2018; Parsaeimehr et al., 2010). The study ID, antimicrobial class (EO or LAB) and specific name, pathogen mean log reduction, storage temperature, exposure time (defined as the time at which the log microbial reduction was quantified in the challenge study), application type (defined as the mode of application of the antimicrobial; namely, milk, film, cheese surface and cheese mixture), antimicrobial concentration and pathogen inoculum level $(\log \mathrm{CFU} / \mathrm{g}$ or $\log \mathrm{CFU} / \mathrm{ml}$ ) were collected for the selected studies. The application type "milk" refers to the direct addition of the antimicrobial agent in bulk milk before curding; while the application type "cheese surface" refers to the practice of applying the tested antimicrobial onto the cheese surface. The category "film" was assigned to those challenges studies where the antimicrobial was embedded in the packaging material through micro- or nano-encapsulation. The application type "cheese mixture" was a special category created to accommodate those challenge studies whose experimental methodology consisted of grinding cheese, inoculating it with the pathogen, and adding the antimicrobial. Thus, "cheese mixture" does not reflect a real mode of application of antimicrobials in the cheese manufacturing process context, but an experimental protocol for challenge studies that researchers have probably devised for being handy although not realistic. Moreover, some of these cheeses were not produced in the laboratory under controlled conditions but purchased for subsequent grinding and inoculation. Table 1 presents summarised information of the types of cheeses, and Table 2 compiles the study characteristics extracted from each primary study and the distribution of mean log reduction data among the different levels for each pathogen. For simplification, the types of application "cheese mixture" and "cheese surface" will be referred to as "mixture" and "surface," respectively.

\subsection{Meta-regression models}

Mixed-effects linear models with weights were separately adjusted to the EOs and added-LAB data sets for each pathogen to evaluate their antimicrobial effects on the square-root of $\log$ reduction $(\sqrt{R})$. Moderators are study characteristics that can be selected and codified from the primary sources in an attempt to explain the between-study variability in effect size. In this meta-analysis, the moderators defined encompassed: application type (App), exposure time $(t)$, antimicrobial concentration $(C)$, storage temperature $(T)$ and inoculum level of the pathogen (Inoc). Log reduction and antimicrobial concentration were square-root and natural-logarithm transformed, respectively, to normalise data distribution and reduce heteroscedasticity. Due to lack of or uneven data, not all levels could be evaluated in the meta-regression. Due to lack of data, no model was produced to describe the antimicrobial effect of added-LAB on SS.

The five meta-regression models adjusted are described below:

$$
\begin{aligned}
& \sqrt{R_{i k}}=\left(\beta_{0}+u_{i}\right)+\beta_{1 k} A p p_{k}+\beta_{2 k}\left\{A p p_{k} \times t\right\}+\left(\beta_{3 k}+v_{i}\right)\left\{A p p_{k} \times L n C\right\} \\
& +\beta_{4} T+\varepsilon_{i k} \\
& \sqrt{R_{i k}}=\left(\beta_{0}+u_{i}\right)+\beta_{1 k} A p p_{k}+\beta_{2 k}\left\{A p p_{k} \times t\right\}+\left(\beta_{3 k}+v_{i}\right)\left\{A p p_{k} \times L n C\right\} \\
& +\beta_{4} T+\beta_{5} \text { Inoc }+\varepsilon_{i k} \\
& \sqrt{R_{i k}}=\left(\beta_{0}+u_{i}\right)+\beta_{1 k} A p p_{k}+\beta_{2 k}\left\{A p p_{k} \times t\right\}+\beta_{3 k}\left\{A p p_{k} \times L n C\right\}+\varepsilon_{i k} \\
& \sqrt{R_{i k}}=\left(\beta_{0}+u_{i}\right)+\beta_{1 k} A p p_{k}+\left(\beta_{2 k}+v_{i}\right)\left\{A p p_{k} \times t\right\}+\beta_{4} T+\beta_{5} \text { Inoc }+\varepsilon_{i k}
\end{aligned}
$$

$\sqrt{R_{i k}}=\left(\beta_{0}+u_{i}\right)+\beta_{1 k} A p p_{k}+\beta_{2 k}\left\{A p p_{k} \times t\right\}+\varepsilon_{i k}$

Eqs. (1), (2) and (3) describe the meta-regression models used to evaluate the antimicrobial effect of added EOs on LM, SA and SS, respectively. Eqs. (1) and (3) contain fewer terms, compared to Eq. (2), as some moderators were not introduced to those models because they were either confounded with other variables or were not significant. The models in Eq. (4) and (5) were used to evaluate the inhibitory effect of added LAB on LM and SA, respectively.

In the above equations, $\beta_{0}$ is an intercept, $\beta_{1 k}$ is the set of fixed effects of the $k$ types of application (a class variable consisting of the levels: cheese mixture, cheese surface, milk and film), and $\beta_{2 k}$ is a set of effects representing the interaction between application type (App) and exposure time $(t)$. In Eqs. (1) to (3), $\beta_{3 k}$ is a set of fixed effects describing the mean interaction between application type (App) and the natural logarithm of the antimicrobial concentration $(\operatorname{LnC})$. Said otherwise, the set of parameters $\beta_{2 k}$ and $\beta_{3 k}$ allow the slopes of exposure time and natural logarithm of antimicrobial concentration, respectively, to take different values depending on the type of application $k$ used. The term $\beta_{4}$ in Eqs. (1), (2) and (4) is the mean effect of a $1{ }^{\circ} \mathrm{C}$ increment in storage temperature on the square-root of log mean reduction, while $\beta_{5}$ in Eqs. (2) and (4) is the effect of a one-log increase in pathogen inoculum level on that same transformed response variable.

The remaining unexplained variability was extracted by placing random-effects $u_{i}$ due to antimicrobial type $i$ in the intercept $\beta_{0}$; and 
Table 3

Test of fixed effects of the meta-regression models predicting the square-root of $\log$ reduction ( $\log \mathrm{CFU} / \mathrm{g}$ or $\mathrm{ml}$ ) of L. monocytogenes, S. aureus and Salmonella spp. in cheese with incorporated essential oils or LAB as a function of moderating variables.

\begin{tabular}{lllll}
\hline Model & Fixed effects & Num/Den DF & F-value & Pr $>$ F \\
\hline \multirow{5}{*}{ EOs-LM } & App & $3 / 704$ & 20.68 & $<.0001$ \\
& App * Exposure Time & $4 / 704$ & 41.00 & $<.0001$ \\
& App * Antimicrobial Conc. & $4 / 704$ & 15.71 & $<.0001$ \\
& Storage Temperature & $1 / 70$ & 23.70 & $<.0001$ \\
& App & $2 / 199$ & 16.01 & $<.0001$ \\
& App * Exposure Time & $3 / 199$ & 105.8 & $<.0001$ \\
EOs-SA & App * Antimicrobial Conc. & $3 / 199$ & 27.61 & $<.0001$ \\
& Storage Temperature & $1 / 199$ & 30.98 & $<.0001$ \\
& Inoculum Level & $1 / 199$ & 5.577 & 0.019 \\
& App & $3 / 4$ & 28.76 & 0.004 \\
EOs-SS & App * Exposure Time & $4 / 339$ & 121.2 & $<.0001$ \\
& App * Antimicrobial Conc. & $4 / 339$ & 236.6 & $<.0001$ \\
& App & $1 / 51$ & 0.130 & 0.720 \\
LAB-LM & App * Exposure Time & $1 / 364$ & 18.52 & $<.0001$ \\
& Storage Temperature & $1 / 364$ & 31.21 & $<.0001$ \\
& Inoculum Level & $1 / 364$ & 11.23 & 0.001 \\
LAB-SA & App & $1 / 62$ & 2.945 & 0.091 \\
& App * Exposure Time & $2 / 62$ & 3.383 & 0.040 \\
\hline
\end{tabular}

random effects $v_{i}$ due to antimicrobial type $i$ either in the time slope $\beta_{2 k}$ or in the concentration slope $\beta_{3 k}$. These random effects $u_{i} v_{i}$ were assumed to be correlated following a normal distribution with mean zero and a variance-covariance matrix $\left[s_{u}^{2}, s_{u v}, s_{v}^{2}\right]$ from where the correlation coefficient $\rho$ of the random effects was calculated. The error term $\varepsilon_{i k}$ accounts for the residuals, and follows a normal distribution with mean zero and variance $s^{2}$. Model parameters, as affected by moderators, were calculated from the fitted meta-regressions, and the significance of moderators was evaluated by analysis of variance $(\alpha=0.05)$.

The antimicrobial effect of EOs was evaluated by analysis of randomeffect marginal intercepts and concentration slopes, organising EOs by origin type. In this analysis, the antimicrobial-specific intercept and slope values are interpreted as deviations $u_{i}$ and $v_{i}$ from the mean values $\beta_{0}$ and $\beta_{3 k}$, respectively. Thus, it was assumed that the higher the $u_{i}$ and $v_{i}$, the stronger the antimicrobial effect of the $\mathrm{EO}_{i}$.

In order to obtain precise estimates of the antimicrobial effect on pathogen inactivation and reflect quality of research design, different weights were assigned to each primary study according to the sample size (number of replicates, $n$ ) used along the experiment to evaluate microbial inactivation. When a primary source did not present the number of replicates sampled to calculate the pathogen reduction, $n=3$ was assigned, as this was the modal value in the database.

To evaluate the fraction of variability in $\sqrt{R}$ that could be explained by the moderators $\left(\mathrm{R}^{2}\right)$, null model versions (no moderators) of Eqs. (1) to (5) were fitted, and $\tau^{2}$ was calculated as $\left(s_{u}^{2}+s_{u v}+s_{v}^{2}\right)$. From the fitted full models (Eqs. (1) to (5)), $\tau^{2}$ res was calculated as $\left(s_{u}^{2}+s_{u v}+s_{v}^{2}\right)$, and finally $\mathrm{R}^{2}$ was estimated as $\left(\tau^{2}-\tau_{\text {res }}^{2}\right) / \tau^{2}$. All meta-regression models described were fitted using the lme function from the nlme package implemented in $\mathrm{R}$ version 3.6.2 (R Core Team 2019).

\section{Results and discussion}

The results of the analysis of variance of the five meta-regression models adjusted are presented in Table 3. The EOs-SA model allowed for the inclusion of the highest number of moderating variables. The EOs-LM model does not contain inoculum level as fixed effect since this term reveal to be non-significant $(p=0.627)$. The EOs-SS model did not include storage temperature, nor inoculum level, as the first variable had only two levels (data was collected at either 4 or $10{ }^{\circ} \mathrm{C}$ ) and the second variable was highly confounded with the antimicrobial application type.
Table 4

Parameter estimates of the meta-regression model predicting the square-root of $\log$ reduction (log $\mathrm{CFU} / \mathrm{g}$ or $\mathrm{ml}$ ) of $L$. monocytogenes in cheese with incorporated essential oils as a function of moderating variables.

\begin{tabular}{|c|c|c|c|c|}
\hline Parameters & Mean & $\begin{array}{l}\text { St. } \\
\text { Error }\end{array}$ & $\begin{array}{l}\operatorname{Pr}>1 \\
\mathrm{t} \mid\end{array}$ & Heterogeneity \\
\hline \multicolumn{4}{|l|}{ Predictors of $\sqrt{\boldsymbol{R}_{i k}}$} & \multirow{23}{*}{$\begin{array}{l}\tau_{\text {res }}^{2}=0.508 \mathrm{R}^{2}> \\
95 \%\end{array}$} \\
\hline$\beta_{0}$ (intercept) & 2.247 & 0.264 & 0.000 & \\
\hline \multicolumn{4}{|l|}{$\beta_{1 \mathrm{k}}$ (application type) } & \\
\hline App: mixture & 0 & - & - & \\
\hline App: film & -1.497 & 0.197 & 0.000 & \\
\hline App: milk & -1.530 & 0.214 & 0.000 & \\
\hline App: surface & -0.466 & 0.185 & 0.012 & \\
\hline \multicolumn{4}{|l|}{$\beta_{2 \mathrm{k}}(\operatorname{app} \times$ exposure time $)$} & \\
\hline App: mixture & 0.236 & 0.069 & 0.001 & \\
\hline App: film & 0.044 & 0.004 & 0.000 & \\
\hline App: milk & 0.007 & 0.002 & 0.000 & \\
\hline App: surface & 0.009 & 0.002 & 0.000 & \\
\hline \multicolumn{4}{|l|}{$\begin{array}{l}\beta_{3 \mathrm{k}} \text { (app } \times \text { antimicrobial } \\
\text { conc.) }\end{array}$} & \\
\hline App: mixture & 0.632 & 0.117 & 0.000 & \\
\hline App: film & -0.095 & 0.115 & 0.409 & \\
\hline App: milk & 0.225 & 0.072 & 0.002 & \\
\hline App: surface & 0.420 & 0.071 & 0.000 & \\
\hline$\beta_{4}$ (storage temperature) & -0.013 & 0.004 & 0.001 & \\
\hline \multicolumn{4}{|l|}{ Variances } & \\
\hline $\mathrm{s}_{\mathrm{u}}$ & 0.713 & & & \\
\hline $\mathrm{s}_{\mathrm{v}}$ & 0.234 & & & \\
\hline$\rho\left(\mathrm{s}_{\mathrm{u}} \mathrm{s}_{\mathrm{v}}\right)$ & 0.791 & & & \\
\hline s (residual) & 0.156 & & & \\
\hline
\end{tabular}

Table 5

Parameter estimates of the meta-regression model predicting the square-root of $\log$ reduction ( $\log \mathrm{CFU} / \mathrm{g}$ or $\mathrm{ml}$ ) of $S$. aureus in cheese with incorporated essential oils as a function of moderating variables.

\begin{tabular}{|c|c|c|c|c|}
\hline Parameters & Mean & $\begin{array}{l}\text { St. } \\
\text { Error }\end{array}$ & $\begin{array}{l}\operatorname{Pr}>1 \\
t \mid\end{array}$ & Heterogeneity \\
\hline \multicolumn{4}{|l|}{ Predictors of $\sqrt{\boldsymbol{R}_{i k}}$} & \multirow{21}{*}{$\begin{array}{l}\tau_{\text {res }}^{2}=0.640 \mathrm{R}^{2}> \\
95 \%\end{array}$} \\
\hline$\beta_{0}$ (intercept) & 2.710 & 0.466 & 0.000 & \\
\hline \multicolumn{4}{|l|}{$\beta_{1 \mathrm{k}}$ (application type) } & \\
\hline App: mixture & 0 & - & - & \\
\hline App: film & -1.530 & 0.187 & 0.000 & \\
\hline App: milk & -0.316 & 0.415 & 0.447 & \\
\hline \multicolumn{4}{|l|}{$\beta_{2 \mathrm{k}}($ app $\times$ exposure time $)$} & \\
\hline App: mixture & 0.229 & 0.046 & 0.000 & \\
\hline App: film & 0.045 & 0.003 & 0.000 & \\
\hline App: milk & 0.014 & 0.002 & 0.000 & \\
\hline \multicolumn{4}{|l|}{$\begin{array}{l}\beta_{3 \mathrm{k}}(\mathrm{app} \times \text { antimicrobial } \\
\text { conc.) }\end{array}$} & \\
\hline App: mixture & 0.516 & 0.077 & 0.000 & \\
\hline App: film & 0.223 & 0.059 & 0.000 & \\
\hline App: milk & 0.405 & 0.064 & 0.000 & \\
\hline$\beta_{4}$ (storage temperature) & 0.012 & 0.010 & 0.246 & \\
\hline$\beta_{5}$ (inoculum level) & -0.134 & 0.059 & 0.025 & \\
\hline \multicolumn{4}{|l|}{ Variances } & \\
\hline $\mathrm{s}_{\mathrm{u}}$ & 0.800 & & & \\
\hline $\mathrm{s}_{\mathrm{v}}$ & 0.096 & & & \\
\hline$\rho\left(\mathrm{s}_{\mathrm{u}} \mathrm{s}_{\mathrm{v}}\right)$ & 0.896 & & & \\
\hline s (residual) & 0.101 & & & \\
\hline
\end{tabular}

In the EOs models, the significance of all terms reveal that these terms or variables have an impact on the microbial reduction promoted by this type of biopreservative. The significant interaction terms "application"exposure time" and "application*antimicrobial concentration" showed that exposure time and antimicrobial concentration not only have a strong effect on the extent of microbial reduction on their own, yet those effects are dependent upon the mode of application of the antimicrobial in the cheese. These significant interaction terms therefore denote that some modes of EOs application are more effective than others.

Regarding the LAB meta-regressions, the data did not allow for the 
Table 6

Parameter estimates of the meta-regression model predicting the square-root of $\log$ reduction ( $\log \mathrm{CFU} / \mathrm{g}$ or $\mathrm{ml}$ ) of Salmonella spp. in cheese with incorporated essential oils as a function of moderating variables.

\begin{tabular}{|c|c|c|c|c|}
\hline Parameters & Mean & $\begin{array}{l}\text { St. } \\
\text { Error }\end{array}$ & $\begin{array}{l}\operatorname{Pr}>1 \\
t \mid\end{array}$ & Heterogeneity \\
\hline \multicolumn{4}{|l|}{ Predictors of $\sqrt{\boldsymbol{R}_{i k}}$} & \multirow{19}{*}{$\begin{array}{l}\tau_{\text {res }}^{2}=0.010 \mathrm{R}^{2}> \\
95 \%\end{array}$} \\
\hline \multicolumn{4}{|l|}{$\beta_{1 \mathrm{k}}$ (application type) } & \\
\hline App: mixture & 0 & - & - & \\
\hline App: film & -0.645 & 0.180 & 0.023 & \\
\hline App: milk & -0.028 & 0.216 & 0.903 & \\
\hline $\begin{array}{l}\text { Application type: } \\
\text { surface }\end{array}$ & 1.224 & 0.152 & 0.001 & \\
\hline \multicolumn{4}{|c|}{$\beta_{2 \mathrm{k}}($ app $\times$ exposure time $)$} & \\
\hline App: mixture & 0.168 & 0.013 & 0.000 & \\
\hline App: film & 0.116 & 0.007 & 0.000 & \\
\hline App: milk & 0.008 & 0.002 & 0.000 & \\
\hline App: surface & 0.008 & 0.007 & 0.233 & \\
\hline \multicolumn{4}{|c|}{$\begin{array}{l}\beta_{3 \mathrm{k}}(\text { app } \times \text { antimicrobial } \\
\text { conc.) }\end{array}$} & \\
\hline App: mixture & 0.167 & 0.063 & 0.008 & \\
\hline App: film & 0.445 & 0.057 & 0.000 & \\
\hline App: milk & 0.332 & 0.067 & 0.000 & \\
\hline App: surface & 0.937 & 0.032 & 0.000 & \\
\hline \multicolumn{4}{|l|}{ Variance } & \\
\hline $\mathrm{s}_{\mathrm{u}}$ & 0.100 & & & \\
\hline s (residual) & 0.131 & & & \\
\hline
\end{tabular}

construction of a model with SS, as only one study referring to the effect of LAB strains on SS growth in cheese was retrieved from the literature search. The LAB-SA model did not include terms for storage temperature because of the small range of temperatures $\left(4\right.$ to $18{ }^{\circ} \mathrm{C}$ ), nor inoculum level because it was confounded with the antimicrobial application type. In the LAB-LM and LAB-SA models, "application" by itself was not found to be significant ( $p=0.720$ and $p=0.091$, respectively). Yet, when the "application*exposure time" interaction was tested, both terms became significant ( $p<0.0001$ and $p=0.040$, respectively). Thus, application type has, in fact, an influence on microbial counts when evaluating the interaction but not when the single moderator is evaluated. The practical meaning of this interaction is that to achieve a certain reduction, distinct exposure times are needed according to the mode of application utilised, as was also observed in the EOs models (Table 3).

\subsection{EOs meta-regression models}

The antimicrobial effects of EOs against LM, SA and SS are presented in Tables 4, 5 and 6, respectively. The effect differed for each pathogen, although, overall, the statistical analysis revealed a clear tendency for microbial reduction when EOs are incorporated in cheese, as revealed by the positive intercepts $\beta_{0}$.

The greater $\beta_{0}$ values for LM and SA (2.247 and 2.710, respectively), compared to SS (1.251), indicate higher antimicrobial effect of essential oils against LM and SA. These results agree with available literature stating that Gram-negative bacteria (such as Salmonella spp.) are more resistant to EOs than Gram-positive bacteria (such as L. monocytogenes and S. aureus) (Nazzaro et al., 2013). The increased antimicrobial effect against Gram-positive bacteria is likely due to differences in cell membrane composition between Gram-positive and Gram-negative bacteria (Nazzaro et al., 2013).

Based on the results of the EOs-LM model (Table 4), it is possible to observe that distinct application types lead to different microbial reductions, as shown by the $\beta_{1 \mathrm{k}}$ values. Notice that the application type "mixture" is considered the "base value", with mean zero, and the remaining application types reflect deviations from that mean. Thus, the incorporation in milk ( $\left.\beta_{1 \mathrm{k}}=-1.530\right)$, within films involving the product $\left(\beta_{1 \mathrm{k}}=-1.497\right)$ or on the cheese surface $\left(\beta_{1 \mathrm{k}}=-0.466\right)$ attained overall lower microbial reduction than the cheese mixture application.
Therefore, caution must be taken by researchers on using the experimental practice of the "cheese mixture" for a challenge study, since it may lead to significantly overestimated values of LM reduction in relation to the real modes of application. From these, applying EO on cheese surface appeared to be more effective against LM than applying in milk or film.

Microbial reduction is time and antimicrobial concentration dependent; thus, we analysed the interaction terms "application type"exposure time" $\left(\beta_{2 \mathrm{k}}\right)$ and "application type*antimicrobial concentration" $\left(\beta_{3 \mathrm{k}}\right)$. The significant $\beta_{2 \mathrm{k}}$ parameter reinforces the impact of application type on microbial reduction by showing that there is an association between this variable and exposure time. The different mean values of $\beta_{2 \mathrm{k}}$ denote the need for distinct exposure times, depending on the application type, to obtain the same microbial reduction. In this case, it is possible to observe that, applying the $\mathrm{EO}$ to the mixture $\left(\beta_{2 \mathrm{k}}=0.236\right)$ or within a film $\left(\beta_{2 \mathrm{k}}=0.044\right)$ results in faster inhibitory effect than applying the EO to the cheese surface $\left(\beta_{2 \mathrm{k}}=0.009\right)$ or into the milk $\left(\beta_{2 \mathrm{k}}=0.007\right)$. Regarding $\beta_{3 \mathrm{k}}$, results reveal that, for the same antimicrobial, different concentrations are required to achieve the same inhibitory effect if the EO is added to the cheese, milk, surface, or within a film. The results highlight that for the same concentration of a specific EO, higher microbial reductions are obtained when the application is in cheese mixture $\left(\beta_{3 \mathrm{k}}=0.632\right)$ or onto the surface $\left(\beta_{3 \mathrm{k}}=0.420\right)$ than in milk $\left(\beta_{3 \mathrm{k}}=0.225\right)$. The mean $\beta_{3 \mathrm{k}}$ for film was found not significant $(p=0.409)$ due to the limited concentration range of EOs tested under this application modality. The $\beta_{4}$ value revealed the negative association between microbial inhibition and temperature, meaning that as storage temperature increases, the microbial inhibitory effect of the EOs is counteracted. Once again, for the time and concentration slopes ( $\beta_{2 \mathrm{k}}$ and $\left.\beta_{3 \mathrm{k}}\right)$, the "cheese mixture" application produced the highest rates of inactivation, which corroborated what was earlier discussed: cheese mixture as a testing procedure that does not mimic the actual manufacturing process, and moreover overestimates microbial reduction, meaning that it is not a suitable methodology for challenge or fate studies. For LM, the increased inhibitory effect of the surface or film application can be explained by the fact that EOs are applied at a later stage of the production process. With application of EOs into milk, a much earlier phase, it is reasonable to say that the antimicrobial properties of the biopreservative may not endure throughout the processes of curding, fermentation and ripening, as EOs are more susceptible to interaction with cheese components and macronutrients, such as proteins and lipids, than when applied onto cheese surface or incorporated in films.

The EOs-SA model (Table 5) showed the recurrent result that the

Table 7

Random effects of the meta-regression models predicting the square-root of log reduction (log CFU/g or $\mathrm{ml}$ ) of L. monocytogenes, S. aureus and Salmonella spp. in cheese with incorporated essential oils.

\begin{tabular}{|c|c|c|c|c|c|}
\hline Essential oil & $\begin{array}{l}\text { LM } \\
\text { Intercept }\end{array}$ & Slope & $\begin{array}{l}\text { SA } \\
\text { Intercept }\end{array}$ & Slope & $\begin{array}{l}\text { SS } \\
\text { Intercept }\end{array}$ \\
\hline Basil & 0.734 & 0.173 & - & - & - \\
\hline Bay & -0.047 & 0.144 & - & - & 0.014 \\
\hline Black cumin seed & -0.073 & -0.239 & -0.753 & -0.070 & 0.000 \\
\hline Cinnamon & -0.061 & 0.083 & - & - & 0.001 \\
\hline Cumin & - & - & 0.001 & 0.005 & - \\
\hline Clove & -0.451 & -0.064 & - & - & 0.106 \\
\hline Hogweed & -0.020 & 0.045 & - & - & - \\
\hline Lemon balm & 0.933 & 0.332 & 0.999 & 0.116 & - \\
\hline Mint & 0.354 & -0.125 & -0.050 & -0.012 & - \\
\hline Oregano & -0.397 & -0.163 & -0.223 & -0.048 & 0.018 \\
\hline Pink pepper & -1.186 & -0.168 & - & - & - \\
\hline Rosemary & -1.080 & -0.281 & - & - & -0.018 \\
\hline Sage & 1.103 & 0.414 & 1.328 & 0.150 & - \\
\hline Tarragon & 0.302 & 0.006 & -0.859 & -0.076 & - \\
\hline Thyme & -0.817 & -0.296 & -0.642 & -0.046 & -0.122 \\
\hline $\begin{array}{l}\text { Zataria multiflora } \\
\text { Boiss. }\end{array}$ & 0.706 & 0.143 & 0.199 & -0.020 & 0.000 \\
\hline
\end{tabular}

*Values in bold highlight the EOs leading to greatest pathogen inhibition. 

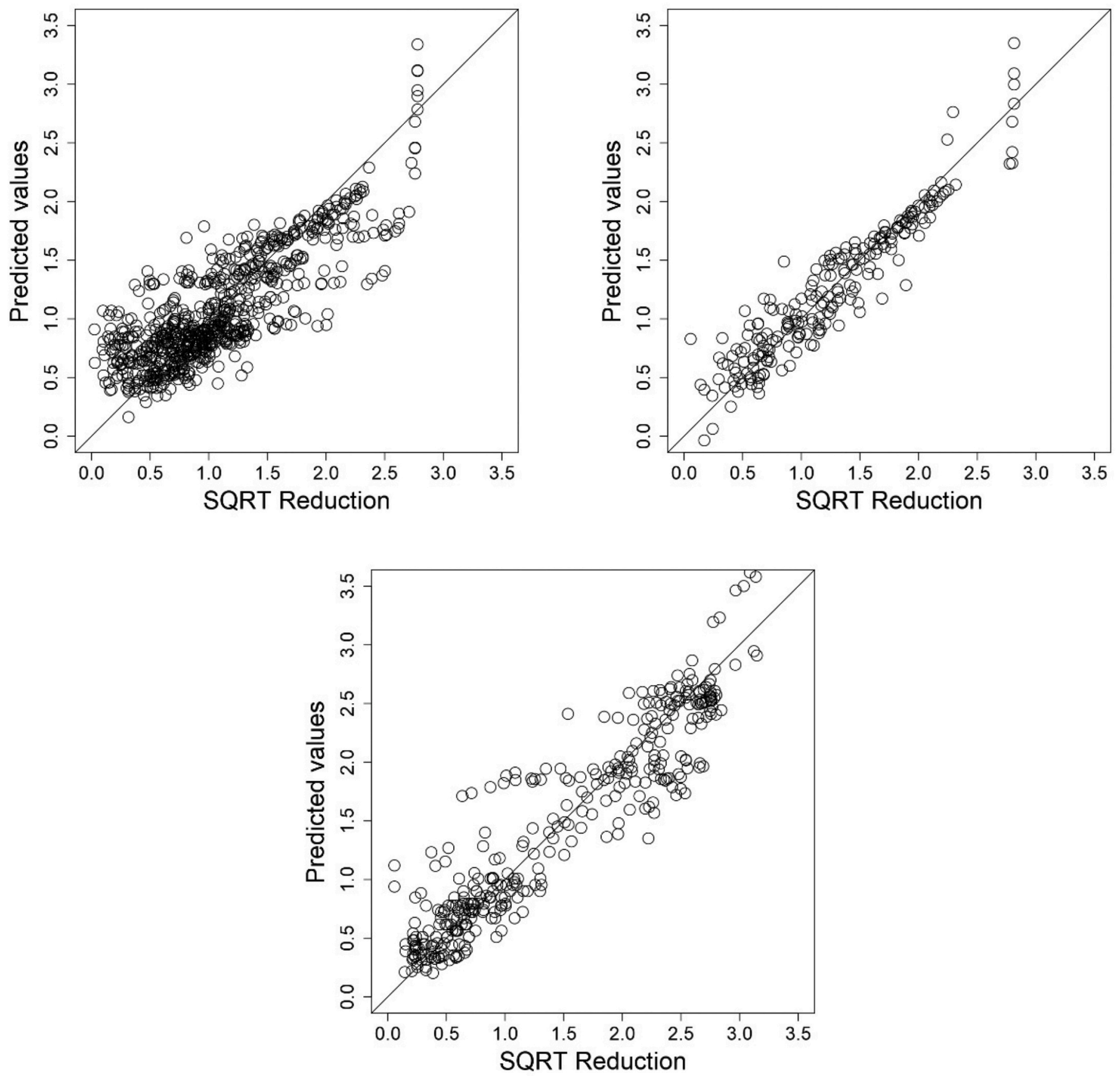

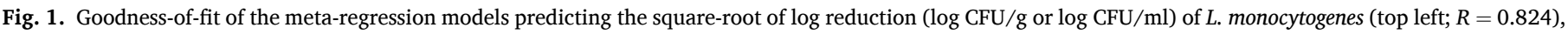
$S$. aureus (top right; $R=0.943$ ) and Salmonella spp. (bottom; $R=0.934$ ) in cheese with incorporated essential oils.

application method of cheese mixture $\left(\beta_{1 \mathrm{k}}=0\right)$ produces higher reductions in SA than incorporation in films $\left(\beta_{1 \mathrm{k}}=-1.530\right)$. Since $\beta_{1 \mathrm{k}}$ for the application in milk was non-significant ( $p=0.447)$, no comparison could be made with the other modes of application. Nonetheless, comparison between the three methods could be made in terms of exposure time and antimicrobial concentration since all terms were highly significant. Again, applying EO in cheese mixture produced the highest slopes $\beta_{2 \mathrm{k}}=0.229$ and $\beta_{3 \mathrm{k}}=0.516$, therefore leading to the greatest microbial reductions. EO incorporation in films $\left(\beta_{2 \mathrm{k}}=0.045\right)$ promoted a faster antimicrobial effect than application in milk $\left(\beta_{2 \mathrm{k}}=0.014\right)$; although, for the same increase in EO concentration applied, higher inactivation effects were found for milk $\left(\beta_{3 \mathrm{k}}=0.495\right)$ than for film $\left(\beta_{3 \mathrm{k}}=0.223\right)$. In this meta-regression for SA, storage temperature was not found to affect microbial reduction $(p=0.246)$; and a negative association between inoculum level and log-reduction was encountered $(p=0.025)$. This indicates an interesting trend that when higher populations of pathogens are inoculated into milk/cheese, the overall inhibitory effect of EOs will be lower. This finding is in disagreement with some studies that have shown that inoculum size has no effect on growth kinetics (Buchanan et al., 1993; Bidlas et al., 2008); nonetheless our results may be explained by the fact that an increase in cell numbers increases the probability of growth, even under suboptimal conditions, and thus limits the antimicrobial inactivation (Koutsoumanis and Sofos, 2005).

Table 6 presents the results for the EOs-SS model. The application of EOs on cheese surface produced significantly higher reduction in Salmonella spp. inoculated populations than EOs containing-films, as can be deduced from the higher values of $\beta_{1 \mathrm{k}}$ and $\beta_{3 \mathrm{k}}$ (1.224 and 0.937 for 
Table 8

Parameter estimates of the meta-regression model predicting the square-root of $\log$ reduction ( $\log \mathrm{CFU} / \mathrm{g}$ or $\mathrm{ml}$ ) of $L$. monocytogenes in cheese with added LAB as a function of moderating variables.

\begin{tabular}{lllll}
\hline Parameters & Mean & $\begin{array}{l}\text { St. } \\
\text { Error }\end{array}$ & $\begin{array}{l}\text { Pr }>\mid \\
\mathrm{t} \mid\end{array}$ & Heterogeneity \\
\hline $\begin{array}{l}\text { Predictors of } \sqrt{\boldsymbol{R}_{\boldsymbol{i k}}} \\
\beta_{0} \text { (intercept) }\end{array}$ & 0.961 & 0.125 & 0.000 & $\mathrm{R}^{2}=27.61 \%$ \\
$\quad \beta_{1 \mathrm{k}}$ (application type) & & & & \\
$\quad$ App: milk & 0 & - & - & \\
$\quad$ App: surface & -0.017 & 0.148 & 0.910 & \\
$\beta_{2 \mathrm{k}}$ (app $\times$ exposure & & & & \\
time) & & & & \\
$\quad$ App: milk & 0.052 & 0.010 & 0.000 & \\
$\quad$ App: surface & 0.046 & 0.015 & 0.003 & \\
$\beta_{3}$ (storage temperature) & 0.025 & 0.004 & 0.000 & \\
$\beta_{4}$ (inoculum level) & -0.067 & 0.020 & 0.001 & \\
Variances & & & & \\
$\mathrm{s}_{\mathrm{u}}$ & 0.430 & & & \\
$\mathrm{~s}_{\mathrm{v}}$ & 0.049 & & & \\
$\rho$ (s $\mathrm{s}_{\mathrm{u}}$ ) & 0.236 & & & \\
$\mathrm{~s}$ (residual) & 0.148 & & & \\
\hline
\end{tabular}

Table 9

Parameter estimates of the meta-regression model predicting the square-root of $\log$ reduction $(\log \mathrm{CFU} / \mathrm{g}$ or $\mathrm{ml}$ ) of $S$. aureus in cheese with added LAB as a function of moderating variables.

\begin{tabular}{lllll}
\hline Parameters & Mean & $\begin{array}{l}\text { St. } \\
\text { Error }\end{array}$ & $\operatorname{Pr}>|\mathrm{t}|$ & Heterogeneity \\
\hline $\begin{array}{l}\text { Predictors of } \sqrt{\boldsymbol{\boldsymbol { R } _ { i k }}} \\
\beta_{0} \text { (intercept) }\end{array}$ & 0.601 & 0.287 & 0.041 & $\mathrm{R}^{2}=11.80 \%$ \\
$\quad \beta_{1 \mathrm{k}}$ (application type) & & & & \\
$\quad$ App: mixture & 0 & - & - & \\
$\quad$ App: milk & 0.239 & 0.289 & 0.411 & \\
$\quad \beta_{2 \mathrm{k}}$ (app $\times$ exposure & & & & \\
$\quad$ time) & & & & \\
$\quad$ App: mixture & 0.001 & 0.013 & 0.915 & \\
$\quad$ App: milk & 0.008 & 0.003 & 0.012 & \\
$\quad$ Variance & & & & \\
$\quad \mathrm{s}_{\mathrm{u}}$ & 0.625 & & & \\
$\quad \mathrm{~s}$ (residual) & 0.173 & & & \\
\hline
\end{tabular}

cheese surface against -0.645 and 0.445 for films, respectively). The term $\beta_{2 \mathrm{k}}$ for cheese surface did not reach significance. Among the realistic EO application types (milk, film and surface), incorporation of EOs in milk produces the lowest inhibitory effect in Salmonella, as this application mode rendered overall the slowest reduction in numbers (lower $\beta_{2 \mathrm{k}}$ at 0.008 ), at the same time that higher concentrations of EO would need to be added in milk in order to attain log reduction levels comparable to the other application modes (lower $\beta_{3 \mathrm{k}}$ at 0.332 ).

Interestingly, some outcomes were consistent across the EOs models built. For the same increase in EO concentration, surface application on cheese is the application method with the greatest inhibitory effect against L. monocytogenes and Salmonella spp., while EO-incorporated films produce a faster inactivation during fermentation/ripening. According to the models, the direct addition of EO to milk render the lowest antimicrobial effect, while cheese mixture was mostly associated with greater microbial inactivation.

The analysis of random-effect marginal intercepts and natural logarithm of antimicrobial concentration slopes for the three EOs models are presented in Table 7. Overall, results show that the EOs antimicrobial action depends on its origin, and there was greater variability among the antimicrobial effects of the EOs for LM and SA control than for SS, as revealed by the broad interval that intercept values can take for the first two pathogens in comparison to the smaller range of values of the SS model. EOs extracted from lemon balm, sage, and a thyme-like plant (Zataria multiflora Boiss.) present the greatest bactericidal effects against LM and SA in cheese matrix. Basil also showed high antimicrobial effect against LM, yet its antimicrobial properties against SA have not been tested in cheese. For the control of SS, the best EO was that of clove. All these EOs belong to the Lamiaceae family, except for clove (Myrtaceae), and nine out of 16 EOs retrieved from this meta-analysis study belong to this taxonomic family. In the last decades, many promising results have been collected about the antioxidant and health-promoting capacities of Lamiaceae's active compounds, which are predominantly polyphenols and present in large amount (Tzima et al., 2018). Generally, phenolic compounds are known to show antimicrobial activity against Gram-positive bacteria (Nazzaro et al., 2013), similarly to the previously discussed results of the EOs meta-regressions, where the greatest bactericidal effect was on LM and SA growth. Overall, it is crucial to consider the bioavailability of essential oils' phenolic compounds and the EO-cheese interaction, as the results from the meta-regressions presented here are specific for cheeses only and may not be accurate if extrapolated to other foods. Moreover, our study gathered information on plant essential oils and not on their specific compounds. Thus, the results are limited by the breadth of the subject itself, and conclusions on the antimicrobial effect of specific plant constituents or compounds may not be appropriate.

In all three meta-regression models, heterogeneity analysis revealed that more than $95 \%$ of the between-EOs variability in microbial log reductions could be explained by the moderators introduced in the models. It is possible to state that the microbial reduction observations retrieved from the literature differed not only due to the different EO origin but also due to the distinct application types, concentration
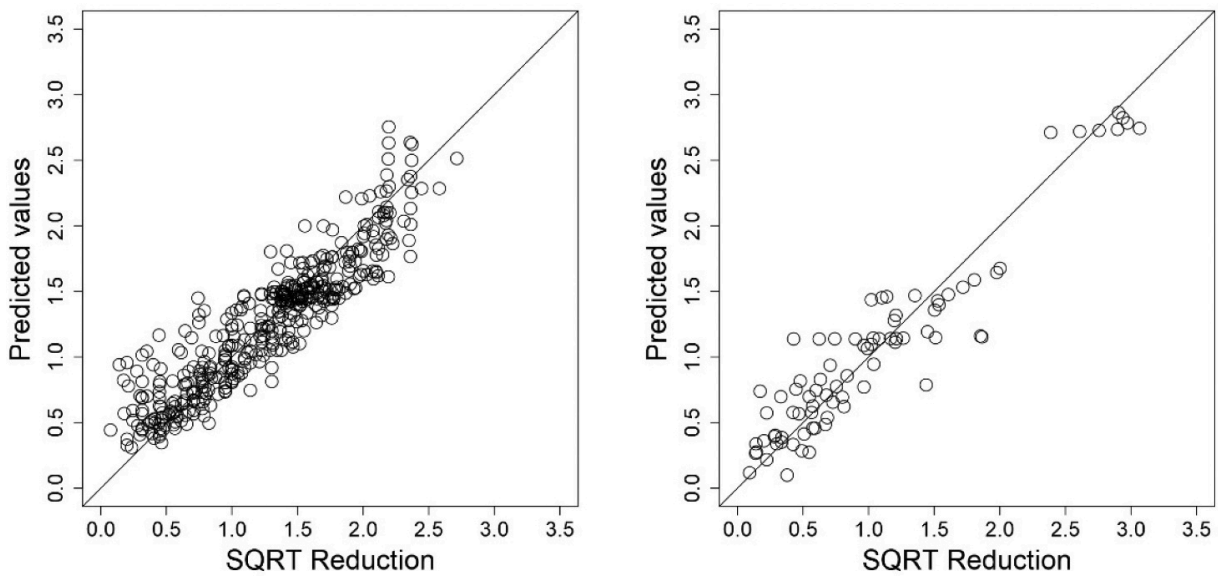

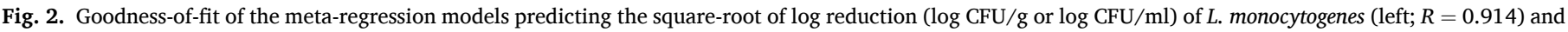
$S$. aureus (right; $R=0.943$ ) in cheese with incorporated LAB. 
applied, exposure time used, storage temperature and inoculum size. This information is valuable as it provides insight on the effectiveness of both application modes and EO origin, which is key when implementing biopreservation hurdle technologies for pathogen control in foods.

In order to evaluate the quality of the meta-regression models built, the goodness-of-fit was assessed, as shown in Fig. 1. The correlation values $\mathrm{R}$ of the goodness-of-fit are particularly high for meta-analysis studies $(R=0.824, R=0.943$ and $R=0.934$ for LM, SA and SS, respectively), so it can be stated that the three models are robust.

\subsection{Added-LAB meta-regression models}

The results regarding the two models built for the antimicrobial effects of added LAB in LM and SA growth are presented in Tables 8 and 9, respectively. As in the EOs models, the positive $\beta_{0}$ intercepts revealed an increase for microbial reduction, thus supporting literature describing the usefulness of bacteriocinogenic LAB strains in cheese. The mean values are, however, lower than those obtained for the EOs models, which could imply that added LAB as biopreservatives have, as a whole, a lower antimicrobial effect than EOs.

The results of the LAB-LM model (Table 8) do not reveal significant differences in the application modes milk and surface as intercepts $\left(\beta_{1 \mathrm{k}}\right)$. However, adding LAB in milk produces a faster inactivation of LM $\left(\beta_{2 \mathrm{k}}=0.052\right)$ than application onto the cheese surface at the end of processing $\left(\beta_{2 \mathrm{k}}=0.046\right)$. Higher storage temperatures (viz. fermentation/ripening) of cheeses in the challenge studies also led to greater microbial reductions $(p<0.0001)$ which could be a consequence of the more rapid proliferation of LAB and their metabolic products, which quickly inactivate LM populations, at least at the initial stages of fermentation. As observed and discussed before for the EOs-SA model, the parameter $\beta_{4}$, associated with the inoculum level, presents a negative mean value, suggesting that higher microbial reductions are counted when the pathogen's inoculum size is lower $(p=0.001)$. The inverse association between inoculation size and microbial log reduction found in this meta-analysis justifies the need for more research to better understand how the inoculum level affects microbial kinetics measurements.

The conclusions that can be driven from the results of the LAB-SA model (Table 9) are quite similar to those derived from the LAB-LM model, in the sense that the two types of application under study (milk and cheese mixture) did not show any significant differences regarding its antimicrobial efficacy in the intercepts $\beta_{1 \mathrm{k}}$ yet adding LAB in milk produces a slightly faster inactivation of $\mathrm{SA}\left(\beta_{2 \mathrm{k}}=0.008\right)$ than the other application mode ( $\beta_{2 \mathrm{k}}$ for mixture was not significantly different from zero). Thus, in challenge studies where the inhibitory effect of LAB is tested, the "cheese mixture" experimental set-up can underestimate the microbial reductions quantified. This is not unexpected since added $\mathrm{LAB}$ exert their antimicrobial action right after their incorporation in milk where, at the expense of lactose, they produce lactic acid that drops the $\mathrm{pH}$, bacteriocins, and other inhibitory compounds that delay the growth of pathogens and provoke their decline. Inoculating LAB after curding and draining (or after cheese is made), as the starting point of a challenge study, is therefore not a sensible practice in face of these results.

The results of the heterogeneity analysis performed for the addedLAB meta-regression models showed that the moderators introduced to the LAB-LM and the LAB-SA models explain $27.61 \%$ and $11.80 \%$ of the variability between the added LAB strains, respectively. These are considerably lower values when compared to the EOs models, revealing, in the first place, that other factors that are not under study here can also have a great impact on the inhibitory effect of LAB strains against pathogens, and could possibly explain a higher percentage of the variability if included in the models. Secondly, it is also plausible that the different added LAB strains studied in the primary studies bring about much more variability in microbial reduction than the various EOs tested.
The goodness-of-fit was also assessed for both models, as shown in Fig. 2, which shows correlation values considered acceptable for metaanalysis studies ( $R=0.914$ and $R=0.943$ for LM and SA, respectively) and that support the robustness of the models.

\section{Conclusion}

Literature data was used to build meta-analytical regression models capable of summarising the reduction in LM, SA and SS populations in cheese attained by added LAB and EOs; and elucidating inhibitory effectiveness by application mode and specific antimicrobial. These meta-regressions showed that the effectiveness of added LAB and EOs were regulated by storage temperature, exposure time, pathogen's inoculum size, antimicrobial concentration and method of application of the biopreservative (cheese mixture, cheese surface, incorporated in film or directly added to milk). EOs-models evidenced that, for a given increase in EO concentration, the application on cheese surface provides the greatest inhibitory effect against LM and SS, whereas EO-embedded films lead to a more rapid inactivation during maturation/storage. Lemon balm, sage and basil EOs showed the best inhibitory outcomes against LM and SA; whilst clove, oregano and bay EOs presented the highest bactericidal effect against SS. In general, the lowest inhibitory effect of EOs against LM, SA and SS is produced when EOs are added to milk. By contrary, and as expected, adding LAB in milk produces a faster inactivation of LM and SA than applying them onto the cheese surface (for LM) or as cheese mixture (for SA).

This meta-analysis has revealed two important issues, one related to experimental design and the other related to directions for further research. The incorporation of the antimicrobial in cheese mixture (this is, grinding cheese after coagulation, draining and shaping), which has been an experimental practice by many researchers as the starting point of the challenge study, is by no means an adequate practice because it tends to overestimate the capacity of EOs to inactivate pathogens while tends to underestimate the capacity of added LAB to inactivate pathogens. Two meta-analysis models pointed out the inverse association between microbial reduction and pathogen's inoculum size, emphasising the need to further investigate how the pathogen's inoculum size affects the measurement of microbial kinetics in challenge studies.

\section{CRediT authorship contribution statement}

Beatriz Nunes Silva: Data curation, Formal analysis, Investigation, Writing - original draft, Validation. Vasco Cadavez: Conceptualization, Data curation, Formal analysis, Investigation, Methodology, Project administration, Writing - review \& editing, Software, Resources, Supervision. José António Teixeira: Project administration, Writing review \& editing, Supervision. Ursula Gonzales-Barron: Conceptualization, Data curation, Formal analysis, Investigation, Methodology, Project administration, Writing - review \& editing, Software, Resources, Supervision.

\section{Declaration of Competing Interests}

None

\section{Acknowledgements}

The authors are grateful to EU PRIMA programme and the Portuguese Foundation for Science and Technology (FCT) for funding the ArtiSane Food project (PRIMA/0001/2018). This study was supported by the Portuguese Foundation for Science and Technology (FCT) under the scope of the strategic funding of UIDB/04469/2020 unit and BioTecNorte operation (NORTE-01-0145-FEDER-000004) funded by the European Regional Development Fund under the scope of Norte2020 Programa Operacional Regional do Norte. Ms. Silva wishes to acknowledge the financial support provided by FCT through the PhD 
grant SFRH/BD/137801/2018. The authors are grateful to FCT and FEDER under Programme PT2020 for financial support to CIMO (UIDB/ 00690/2020). Dr. Gonzales-Barron acknowledges the national funding by FCT, P.I., through the Institutional Scientific Employment Programme contract.

\section{References}

Izquierdo, E., Marchioni, E., Aoude-Werner, D., Hasselmann, C., Ennahar, S., 2009. Smearing of soft cheese with Enterococcus faecium WHE 81, a multi-bacteriocin producer, against Listeria monocytogenes. Food Microbiol 26 (1), 16-20. https://doi. org /10.1016/j.fm.2008.08.002.

Kim, H., Beak, S.E., Yang, S.Y., Song, K.B., 2018. Application of an antimicrobial packaging material from chicken bone gelatine and cinnamon bark oil to mozzarella cheese. Int. J. Food Sci. Technol. 53, 619-625. https://doi.org/10.1111/ijfs.13636.

Achemchem, F., Abrini, J., Martínes-Bueno, M., Valdivia, E., Maqueda, M., 2006. Control of Listeria monocytogenes in goat's milk and goat's Jben by the bacteriocinogenic Enterococcus faecium F58 strain. J. Food Prot. 69 (10), 2370-2376. https://doi.org/ 10.4315/0362-028X-69.10.2370.

Almeida, G., et al., 2007. Microbiological characterization of randomly selected Portuguese raw milk cheeses with reference to food safety. J. Food Prot. 70 (7), 1710-1716. https://doi.org/10.4315/0362-028X-70.7.1710.

Tekinşen, K.K., Özdemir, Z., 2006. Prevalence of foodborne pathogens in Turkish Van otlu (Herb) cheese. Food Control 17 (9), 707-711. https://doi.org/10.1016/j. foodcont.2005.04.007.

Coelho, M.C., Silva, C.C.G, Ribeiro, S.C., Dapkevicius, M.L.N.E., Rosa, H.J.D., 2014. Control of Listeria monocytogenes in fresh cheese using protective lactic acid bacteria Int. J. Food Microbiol. 191, 53-59. https://doi.org/10.1016/j. ijfoodmicro.2014.08.029.

Cremonesi, P., et al., 2007. Detection of enterotoxigenic Staphylococcus aureus isolates in raw milk cheese. Lett. Appl. Microbiol. 45 (6), 586-591. https://doi.org/10.1111/ j.1472-765X.2007.02231.x.

Xavier, C., Gonzales-Barron, U., Paula, V., Estevinho, L., Cadavez, V., 2014. Metaanalysis of the incidence of foodborne pathogens in Portuguese meats and their products. Food Res. Int. 55, 311-323. https://doi.org/10.1016/j. foodres.2013.11.024.

United States Food and Drug Administration, 2003. Bad bug book: foodborne pathogenic microorganisms and natural toxins. Available: https://www.fda.gov/media/83271 /download.

de Souza, G.T., et al., 2016. Effects of the essential oil from Origanum vulgare L. on survival of pathogenic bacteria and starter lactic acid bacteria in semihard cheese broth and slurry. J. Food Prot 79 (2), 246-252. https://doi.org/10.4315/0362-028X. JFP-15-172.

Duquenne, M., et al., 2010. Tool for quantification of staphylococcal enterotoxin gene expression in cheese. Appl. Environ. Microbiol. 76 (5), 1367-1374. https://doi.org/ 10.1128/AEM.01736-09.

Nazzaro, F., Fratianni, F., De Martino, L., Coppola, R., De Feo, V., 2013. Effect of essential oils on pathogenic bacteria. Pharmaceuticals 6 (12), 1451-1474. https:// doi.org/10.3390/ph6121451.

Parsaeimehr, M., et al., 2010. Effect of Zataria multiflora Boiss. essential oil, nisin, and their combination on the production of enterotoxin $\mathrm{C}$ and alpha-hemolysin by Staphylococcus aureus. Foodborne Pathog. Dis. 7 (3), 299-305. https://doi.org/ 10.1089/fpd.2009.0416.

Paulin, S., Horn, B., Hudson, J.A., 2012. Factor Influencing Staphylococcal Enterotoxin Production in Dairy Products. Client report no.: FW 11034. Institute of Environmental Science and Research, New Zealand.

Tulini, F., 2014. Isolation of lactic acid bacteria from milk and cheese with potential for food biopreservation and utilization for increasing whey digestibility. Doctoral Thesis presented to the Graduate Program in Biosciences Applied to Pharmacy (University of São Paulo) and to the École Doctoral Santé. InformationCommunication, Mathematiques, Matières (Université de Bretagne Occidentale). https://doi.org/10.13140/RG.2.2.12624.30729.

Han, J.H., Patel, D., Kim, J.E., Min, S.C., 2014. Retardation of Listeria monocytogenes growth in mozzarella cheese using antimicrobial sachets containing rosemary oil and thyme oil. J. Food Sci. 79 (11), E2272-E2278. https://doi.org/10.1111/1750 3841.12659.

Han, J.H., Patel, D., Kim, J.E., Min, S.C., 2015. Microbial inhibition in mozzarella cheese using rosemary and thyme oils in combination with sodium diacetate. Food Sci Biotechnol. 24 (1), 75-84. https://doi.org/10.1007/s10068-015-0012-4.

Hassanien, M.F.R., Mahgoub, S.A., El-Zahar, K.M., 2014. Soft cheese supplemented with black cumin oil: impact on food borne pathogens and quality during storage. Saudi J. Biol. Sci. 21 (3), 280-288. https://doi.org/10.1016/j.sjbs.2013.10.005.

Hassanzadazar, H., Ehsani, A., Mardani, K., 2014. Antibacterial activity of Enterococcus faecium derived from Koopeh cheese against Listeria monocytogenes in probiotic ultrafiltrated cheese. Vet. Res. Forum 5 (3), 169-175.

Iannetti, L., et al., 2016. Listeria monocytogenes in ready-to-eat foods in Italy: prevalence of contamination at retail and characterisation of strains from meat products and cheese. Food Control 68, 55-61. https://doi.org/10.1016/j.foodcont.2016.03.036.

Ibrahim, A., Awad, S., 2018. Selection and identification of protective culture for controlling Staphylococcus aureus in fresh Domiati like cheese. J. Food Saf. 38 (1) https://doi.org/10.1111/jfs.12418.

Bidlas, E., Du, T., Lambert, R.J.W., 2008. An explanation for the effect of inoculum size on MIC and the growth/no growth interface. Int. J. Food Microbiol. 126 (1-2), 140-152. https://doi.org/10.1016/j.ijfoodmicro.2008.05.023.
Buchanan, R.L., Bagi, L.K., Goins, R.V., Phillips, J.G., 1993. Response surface models for the growth kinetics of Escherichia coli O157:H7. Food Microbiol. 10 (4), 303-315. https://doi.org/10.1006/fmic.1993.1035.

Campagnollo, F.B., et al., 2018. Selection of indigenous lactic acid bacteria presenting anti-listerial activity, and their role in reducing the maturation period and assuring the safety of traditional Brazilian cheeses. Food Microbiol. 73, 288-297. https://doi. $\operatorname{org} / 10.1016 / j . f m .2018 .02 .006$.

Artiga-Artigas, M., Acevedo-Fani, A., Martín-Belloso, O., 2017. Improving the shelf life of low-fat cut cheese using nanoemulsion-based edible coatings containing oregano essential oil and mandarin fiber. Food Control 76, 1-12. https://doi.org/10.1016/j. foodcont.2017.01.001.

Aspri, M., et al., 2017. Application of bacteriocin-producing Enterococcus faecium isolated from donkey milk, in the bio-control of Listeria monocytogenes in fresh whey cheese. Int. Dairy J. 73, 1-9. https://doi.org/10.1016/j.idairyj.2017.04.008.

Tzima, K., Brunton, N.P., Rai, D.K., 2018. Qualitative and quantitative analysis of polyphenols in Lamiaceae plants - a review. Plants 7 (2), 30. https://doi.org/ 10.3390 /plants7020025.

Medvedová, A., Valík, L., Liptakova, D., 2011. Study of the Fresco culture inhibitory effect against Staphylococcus aureus in milk and in lump cheeses. J. Food Nutr. Res, 50 (4), 193-198.

Menon, K.V., Garg, S.R., 2001. Inhibitory effect of clove oil on Listeria monocytogenes in meat and cheese. Food Microbiol 18 (6), 647-650. https://doi.org/10.1006/ fmic.2001.0430.

Smith-Palmer, A., Stewart, J., Fyfe, L., 2001. The potential application of plant essential oils as natural food preservatives in soft cheese. Food Microbiol. 18 (4), 463-470. https://doi.org/10.1006/fmic.2001.0415.

Tehrani, F., Sadeghi, E., 2015. Effect of mint essential oil on growth of Listeria monocytogenes during the ripening and storage of Iranian white brined cheese. J. Appl. Environ. Biol. Sci. 5, 150-154.

Wahba, N.M., Ahmed, A.S., Ebraheim, Z.Z., 2010. Antimicrobial effects of pepper, parsley, and dill and their roles in the microbiological quality enhancement of traditional Egyptian Kareish cheese. Foodborne Pathog. Dis. 7 (4), 411-418. https:// doi.org/10.1089/fpd.2009.0412, 10.1089=fpd.2009.0412.

Dannenberg, G.S., Funck, G.D, Mattei, F.J., da Silva, W.P., Fiorentini, A.M., 2016 Antimicrobial and antioxidant activity of essential oil from pink pepper tree (Schinus terebinthifolius Raddi) in vitro and in cheese experimentally contaminated with Listeria monocytogenes. Innov. Food Sci. Emerg. Technol. 36, 120-127. https://doi. org/10.1016/j.ifset.2016.06.009.

de Carvalho, R.J., et al., 2015. Comparative inhibitory effects of Thymus vulgaris L. essential oil against Staphylococcus aureus, Listeria monocytogenes and mesophilic starter co-culture in cheese-mimicking models. Food Microbiol. 52, 59-65. https:// doi.org/10.1016/j.fm.2015.07.003.

Elafify, M., et al., 2019. Prevalence of Salmonella spp. in Egyptian dairy products: molecular, antimicrobial profiles and a reduction trial using D-tryptophan. J. Consum. Prot. Food Saf. 14, 399-407. https://doi.org/10.1007/s00003-01901248-y.

Cunha-Neto, A., et al., 2019. Salmonella Anatum, S. Infantis and S. Schwarzengrund in Brazilian cheeses: occurrence and antibiotic resistance profiles. Int. J. Dairy Technol. 70, 1-5. https://doi.org/10.1111/1471-0307.12636.

Tetili, F., Bendali, F., Perrier, J., Sadoun, D., 2017. Anti-Staphylococcal enterotoxinogenesis of Lactococcus lactis in Algerian raw milk cheese. Food Technol. Biotechnol. 55 (4), 511-518. https://doi.org/10.17113/ftb.55.04.17.5105.

Torlak, E., Nizamlioglu, M., 2011. Antimicrobial effectiveness of chitosan-essential oil coated plastic films against foodborne pathogens. J. Plast. Film \& Sheeting. 27 (3), 235-248. https://doi.org/10.1177/8756087911407391.

Jackson, K.A., Gould, L.H., Hunter, J.C., Kucerova, Z., Jackson, B., 2018. Listeriosis outbreaks associated with soft cheeses, United States, 1998-2014. Emerg. Infect. Dis. 24 (6), 1116-1118. https://doi.org/10.3201/eid2406.171051.

Kavas, G., Kavas, N., 2016. Use of egg white protein powder based films fortified with sage and lemon balm essential oils in the storage of lor cheese. Mljekarstvo 66 (2), 99-111. https://doi.org/10.15567/mljekarstvo.2016.0202.

Rosengren, Å., Fabricius, A., Guss, B., Sylvén, S., Lindqvist, R., 2010. Occurrence of foodborne pathogens and characterization of Staphylococcus aureus in cheese produced on farm-dairies. Int. J. Food Microbiol. 144 (2), 263-269. https://doi.org/ 10.1016/j.ijfoodmicro.2010.10.004.

Sadeghi, E., Basti, A.A., Noori, N., Khanjari, A., Partovi, R., 2013. Effect of Cuminum cyminum L. essential oil and Lactobacillus acidophilus (a probiotic) on Staphylococcus aureus during the manufacture, ripening and storage of white brined cheese. J. Food Process. Preserv 37 (5), 449-455. https://doi.org/10.1111/j.17454549.2011.00664.x.

Sadeghi, E., Mohammadi, A., Jamilpanah, M., Bashiri, M., Bohlouli, S., 2016. Antimicrobial effects of Mentha pulegium essential oil onListeria monocytogenes in Iranian white cheese. J. Food Qual. Hazards Control. 3 (1), 20-24.

Scatassa, M.L., et al., 2017. Anti-Listeria activity of lactic acid bacteria in two traditional Sicilian cheeses. Ital. J. Food Saf. 6 (1), 6191. https://doi.org/10.4081/ ijfs.2017.6191.

Ehsani, A., et al., 2019. Antibacterial activity and sensory properties of Heracleum persicum essential oil, nisin, and Lactobacillus acidophilus against Listeria monocytogenes in cheese. Vet. World 12 (1), 90-96. https://doi.org/10.14202/ vetworld.2019.90-96.

Ehsani, A., Hashemi, M., Naghibi, S.S., Mohammadi, S., Sadaghiani, S.K., 2016. Properties of Bunium Persicum essential oil and its application in Iranian white cheese against Listeria monocytogenes and Escherichia coli O157:H7. J. Food Saf. 36 (4), 563-570. https://doi.org/10.1111/jfs.12277.

Ehsani, A., Mahmoudi, R., 2013. Effects of Mentha longifolia L. essential oil and Lactobacillus casei on the organoleptic properties and on the growth of Staphylococcus 
aureus and Listeria monocytogenes during manufacturing, ripening and storage of Iranian white-brined cheese. Int. J. Dairy Technol. 66 (1), 70-76. https://doi.org/ 10.1111/j.1471-0307.2012.00865.x.

Hamedi, H., Razavi-Rohani, S.M., Gandomi, H., 2014. Combination effect of essential oils of some herbs with monolaurin on growth and survival of Listeria monocytogenes in culture media and cheese. J. Food Process. Preserv. 38 (1), 304-310. https://doi. org/10.1111/j.1745-4549.2012.00778.x.

Hamedo, H.A., Abdelmigid, H.M., 2009. Use of antimicrobial and genotoxicity potentiality for evaluation of essential oils as food preservatives. Open Biotechnol. J. 3, 50-56. https://doi.org/10.2174/1874070700903010050.

da Costa, W.K.A, et al., 2018. Exploiting the antagonistic activity of fruit-derived Lactobacillus to control pathogenic bacteria in fresh cheese and chicken meat. Food Res. Int. 108, 172-182. https://doi.org/10.1016/j.foodres.2018.03.045.

EFSA and ECDC, 2018. The European union summary report on trends and sources of zoonoses, zoonotic agents and food-borne outbreaks in 2017. European Food Safety Authority and European Centre for Disease Prevention and Control. EFSA J. 16 (12), 5500. https://doi.org/10.2903/j.efsa.2018.5500.

Pingitore, E.V., Todorov, S.D., Sesma, F., Franco, B.D.G.M., 2012. Application of bacteriocinogenic Enterococcus mundtii CRL35 and Enterococcus faecium ST88Ch in the control of Listeria monocytogenes in fresh Minas cheese. Food Microbiol. 32 (1), 38-47. https://doi.org/10.1016/j.fm.2012.04.005.

Raeisi, M., et al., 2014. Essential oil of tarragon (Artemisia dracunculus) antibacterial activity on Staphylococcus aureus and Escherichia coli in culture media and Iranian white cheese. Iran. J. Microbiol. 4 (1), 30-34.

Rilla, N., Martínez, B., Rodríguez, A., 2004. Inhibition of a methicillin-resistant Staphylococcus aureus strain in Afuega'l Pitu cheese by the nisin Z-producing strain Lactococcus lactis subsp. lactis IPLA 729. J. Food Prot. 67 (5), 928-933. https://doi. org/10.4315/0362-028X-67.5.928.

Rodríguez, E., et al., 2005. Antimicrobial activity of pediocin-producing Lactococcus lactis on Listeria monocytogenes, Staphylococcus aureus and Escherichia coli O157:H7 in cheese. Int. Dairy J. 15 (1), 51-57. https://doi.org/10.1016/j.idairyj.2004.05.004.

Rolim, F.R.L., et al., 2015. Survival of Lactobacillus rhamnosus EM1107 in simulated gastrointestinal conditions and its inhibitory effect against pathogenic bacteria in semi-hard goat cheese. LWT - Food Sci Technol. 63 (2), 807-813. https://doi.org/ 10.1016/j.lwt.2015.05.004.

Langa, S., et al., 2018. Protective effect of reuterin-producing Lactobacillus reuteri against Listeria monocytogenes and Escherichia coli O157 : H7 in semi-hard cheese. Food Control 84, 284-289. https://doi.org/10.1016/j.foodcont.2017.08.004.

Gonzales-Barron, U., Gonçalves-Tenório, A., Rodrigues, V., Cadavez, V., 2017. Foodborne pathogens in raw milk and cheese of sheep and goat origin: a metaanalysis approach. Curr. Opin. Food Sci. 18, 7-13. https://doi.org/10.1016/j. cofs.2017.10.002.

Govaris, A., Botsoglou, E., Sergelidis, D., Chatzopoulou, P.S., 2011. Antibacterial activity of oregano and thyme essential oils against Listeria monocytogenes and Escherichia coli O157:H7 in Feta cheese packaged under modified atmosphere. LWT - Food Sci. Technol. 44 (4), 1240-1244. https://doi.org/10.1016/j.lwt.2010.09.022.

Gustafson, J.E., et al., 1998. Effects of tea tree oil on Escherichia coli. Lett. Appl. Microbiol. 26, 194-198. https://doi.org/10.1046/j.1472-765X.1998.00317.x.

Dal Bello, B, et al., 2012. Technological characterization of bacteriocin producing Lactococcus lactis strains employed to control Listeria monocytogenes in Cottage cheese. Int. J. Food Microbiol. 153 (1-2), 58-65. https://doi.org/10.1016/j. ijfoodmicro.2011.10.016.

Castro, R.C.S., et al., 2018. Lactic acid bacteria as biological control of Staphylococcus aureus in Coalho goat cheese. Food Technol. Biotechnol. 56 (3), 431-440. https:// doi.org/10.17113/ftb.56.03.18.5736.

Abdelfatah, E.N., Mahboub, H.H.H., 2018. Studies on the effect of Lactococcus garvieae of dairy origin on both cheese and Nile tilapia (O. niloticus). Int J Vet Sci Med. 6 (2), 201-207. https://doi.org/10.1016/j.ijvsm.2018.11.002.
Liu, L., O'Conner, P., Cotter, P.D., Hill, C., Ross, R.P., 2008. Controlling Listeria monocytogenes in Cottage cheese through heterologous production of enterocin A by Lactococcus lactis. J. Appl. Microbiol. 104 (4), 1059-1066. https://doi.org/10.1111/ j.1365-2672.2007.03640.x.

Lourenco, A., Kamnetz, M.B., Gadotti, C., Diez-Gonzalez, F., 2017. Antimicrobial treatments to control Listeria monocytogenes in queso fresco. Food Microbiol. 64, 47-55. https://doi.org/10.1016/j.fm.2016.12.014.

Ghasemi, S., Javadi, N.H.S, Moradi, M., Khosravi-Darani, K., 2015. Application of zein antimicrobial edible film incorporating Zataria multiflora boiss essential oil for preservation of Iranian ultrafiltered Feta cheese. African J. Biotechnol. 14 (24), 2014-2021. https://doi.org/10.5897/ajb2014.13992.

Gomes de Oliveira, M.E., et al., 2014. Addition of probiotic bacteria in a semi-hard goat cheese (Coalho): survival to simulated gastrointestinal conditions and inhibitory effect against pathogenic bacteria. Food Res. Int. 64, 241-247. https://doi.org/ 10.1016/j.foodres.2014.06.032.

Morandi, S., Silvetti, T., Battelli, G., Brasca, M., 2019. Can lactic acid bacteria be an efficient tool for controlling Listeria monocytogenes contamination on cheese surface? The case of Gorgonzola cheese. Food Control 96, 499-507. https://doi.org/10.1016/ j.foodcont.2018.10.012.

Nassim, M., Rihab, B., 2017. Identification of potential biopreservative lactic acid bacteria strains isolated from Algerian cow's milk and demonstration of antagonism against S. aureus in Cheese. Food Sci. Technol. Res. 23 (5), 679-688. https://doi.org/ 10.3136/fstr.23.679.

Mahgoub, S.A., Ramadan, M.F., El-Zahar, K.M., 2013. Cold pressed Nigella sativa oil inhibits the growth of foodborne pathogens and improves the quality of Domiati cheese. J. Food Saf. 33 (4), 470-480. https://doi.org/10.1111/jfs.12078.

Mahmoudi, R., Tajik, H., Ehsani, A., Zare, P., 2012. Physicochemical and hygienic effects of Lactobacillus acidophilus in Iranian white cheese. Vet. Res. Forum 3 (3), 193-197.

Martinez, R.C., et al., 2015. Bacteriocin production and inhibition of Listeria monocytogenes by Lactobacillus sakei subsp. sakei 2a in a potentially symbiotic cheese spread. Food Microbiol. 48, 143-152. https://doi.org/10.1016/j.fm.2014.12.010.

Khay, E.O., Idaomar, M., Moussaoui, N.E., Abrini, J., 2014. Application of a bacteriocinlike inhibitory substance producing Enterococcus durans E204 strain, isolated from camel milk, to control Listeria monocytogenes CECT 4032 in goat Jben. Ann. Microbiol. 64 (1), 313-319. https://doi.org/10.1007/s13213-013-0666-1.

R Core Team. R: A Language and Environment for Statistical Computing. R Foundation For Statistical Computing, Vienna, Austria. [Internet]. Published in2019. Available: http://www.r-project.org/.

Atanasova, J., Moncheva, P., Ivanova, I., 2014. Proteolytic and antimicrobial activity of lactic acid bacteria grown in goat milk. Biotechnol. Biotechnol. Equip. 28 (6), 1073-1078. https://doi.org/10.1080/13102818.2014.971487.

Azizkhani, M., Tooryan, F., Azizkhani, M., 2016. Inhibitory potential of Salvia sclarea and Ocimum basilicum against chemical and microbial spoilage in cheese. J Food Saf 36 (1), 109-119. https://doi.org/10.1111/jfs.12218.

Ben Slama, R., Kouidhi, B., Zmantar, T., Chaieb, K., Bakhrouf, A., 2013. Anti-listerial and Anti-biofilm activities of potential probiotic Lactobacillus strains isolated from Tunisian traditional fermented food. J. Food Saf. 33 (1), 8-16. https://doi.org/ $10.1111 /$ jfs. 12017

Benkerroum, N., Oubel, N., Zahar, M., Dlia, S., Filali-Maltouf, A., 2000. Isolation of a bacteriocin-producing Lactococcus lactis subsp. lactis to control Listeria monocytogenes in Moroccan Jben. . J. Appl. Microbiol. 89 (6), 960-968. https://doi.org/10.1046/ j.1365-2672.2000.01199.x.

Kousta, M., Mataragas, M., Skandamis, P., Drosinos, E.H., 2010. Prevalence and sources of cheese contamination with pathogens at farm and processing levels. Food Control 21 (6), 805-815. https://doi.org/10.1016/j.foodcont.2009.11.015.

Koutsoumanis, K.P., Sofos, J.N., 2005. Effect of inoculum size on the combined temperature, pH and aw limits for growth of Listeria monocytogenes. Int. J. Food Microbiol. 104 (1), 83-91. https://doi.org/10.1016/j.ijfoodmicro.2005.01.010. 